\title{
Measuring cortisol in fish scales to study stress in wild tropical tuna
}

\author{
Emmanuelle Roque d'orbcastel (1D) Yvan Bettarel • Marion Dellinger • \\ Bastien Sadoul · Thierry Bouvier · Justin Monin Amandé · Laurent Dagorn • \\ Benjamin Geffroy
}

Received: 23 October 2020 / Accepted: 1 June 2021 / Published online: 22 June 2021

(C) The Author(s), under exclusive licence to Springer Nature B.V. 2021

\begin{abstract}
Cortisol is recognized as a physiological indicator of stress in fish. However, this hormone is typically measured in plasma samples. In this study, cortisol content was evaluated for the first time in the scales of tropical tuna. The sample included 20 skipjack tuna (Katsuwonus pelamis) and 25 yellowfin tuna (Thunnus albacares) collected in the Atlantic (the Gulf of Guinea off the Ivory Coast) and the Indian Ocean (off Reunion Island), and their scales were analyzed using an ELISA test. The results indicated that on average, cortisol concentration (1) did not show any geographical pattern, (2) was independent of fish size, and (3) was significantly higher in
\end{abstract}

E. Roque d'orbcastel $(\bowtie) \cdot$ Y. Bettarel $\cdot$ M. Dellinger ·

B. Sadoul · T. Bouvier · L. Dagorn · B. Geffroy

MARBEC Univ Montpellier, CNRS, Ifremer, IRD, Sète,

France

e-mail: emmanuelle.roque@ifremer.fr

M. Dellinger

Department of Aquaculture and Fish Biology, Hólar

University, Hólar, Iceland

B. Sadoul

ESE, Ecology and Ecosystem Health, Inrae, Institut Agro, Rennes, Brittany, France

J. M. Amandé

Centre de Recherches Océanologiques (CRO), DRAV, 29,

Rue des pêcheurs, BP V 18, Abidjan, Côte d'Ivoire

J. M. Amandé

Cocody 2 Plateaux Aghien, 01 BP 3012 Abidjan 01,

Abidjan, Côte d'Ivoire skipjack (mean $4.75 \pm 6.56 \mathrm{ng} \mathrm{g}^{-1}$ ) than in yellowfin (mean $1.65 \pm 1.85 \mathrm{ng} \mathrm{g}^{-1}$ ), although the difference was mainly due to four skipjack individuals. Larger datasets would be needed to confirm any species difference in cortisol concentration. The particularly high cortisol concentration observed in four individuals may be due to fish from different schools, suggesting the need for future sampling from free-swimming schools to investigate intra- and inter-school variability in cortisol concentration. This study opens the door for future research, including the collection of scales on tagged individuals, to investigate the links between chronic stress and behavior in these species.

Keywords Fish scales · Cortisol · Tress · Welfare · Kipjack tuna Yellowfin tuna

\section{Introduction}

The capacity of fish to cope with environmental challenges is of primary importance in a rapidly changing world. The stress axis plays a central role in the coping capacity of fish, as it diverts energy from growth and reproduction to cope with acute environmental changes (Sadoul and Vijayan 2016). The two stress-related response mechanisms in fish are brainsympathetic chromaffin cells (BSC) and the hypothalamus-pituitary-interrenal (HPI) axis. The underlying mechanisms of the stress axis in fish have been well described (Barton 2002; Schreck and Tort 2016). At 
the physiological level, the primary response to a stressor in fish is neuroendocrinal and involves the activation by the central nervous system of the sympathetic nervous system, releasing neurotransmitters and hormones such as catecholamine and corticosteroids (mainly cortisol in fish). Following the stimulus, plasma cortisol increases after a period of time ranging from a few minutes to an hour, depending on the species and the intensity and/or duration of the stimuli (Barton 2002). Cortisol is considered a good quantitative indicator of acute and chronic physiological stress (Ellis et al. 2012). Until recently, this hormone was mainly measured in the plasma of unstressed and stressed fish, providing a basal and high cortisol level. Yet, plasma measures of cortisol can only provide insight into the stress level of the fish at a given time. In an ecological context, an integrative value of stress over a long period is much more valuable, allowing a more comprehensive idea of the life history of the animal. Recently, new matrices have emerged to measure cortisol; these are being used as relatively non-invasive markers of stress (Sadoul and Geffroy 2019). Among these markers, fish scales are the most promising matrix as they provide a record of the integrated stress response over time (i.e., from weeks to months, Aerts et al. 2015) and a grid to highlight behavioral ecology regarding exposure to stress factors such as temperature (Goikoetxea et al. 2020), since the metabolic clearance rate in scales is much slower than in plasma (Laberge et al. 2019). Previous studies have shown that intra-specific differences in basal cortisol are genetically driven (Øverli et al. 2002a) and are generally aligned with differences in behavior or coping style, in which reactive individuals display higher basal cortisol levels compared to proactive individuals (Koolhaas et al. 1999). In trout, for instance, longterm cortisol administration was shown to decrease both locomotor activity and aggression (Øverli et al. 2002b). This could be transcribed at the scale level with cortisol accumulation.

Tuna are present in all oceans, and as top predators, they play a major ecological role in offshore pelagic ecosystems. Worldwide, tuna species are exploited by both artisanal and industrial fisheries, using different types of fishing gear. Two tuna species, skipjack (SKJ, Katsuwonus pelamis) and yellowfin (YFT, Thunnus albacares), are among the most landed species in the world (FAO 2018). Although the biology and ecology of tuna have been extensively investigated, particularly to provide scientific advice for fishery management and the conservation of stocks, studies measuring cortisol in tuna are scarce and limited to only one species (Atlantic bluefin tuna, Thunnus thynnus) in one environment (Kirchhoff et al. 2011; Addis et al. 2013; Tracey et al. 2016). By measuring the basal levels of plasma cortisol, these studies showed a rapid accumulation of cortisol in response to an intense one-off event (capture) and focused on the short-term stress reaction to capture. In general, captured fish are exposed to stressful stimuli, e.g., physical trauma and physiological stress (Skomal 2007), which is worth investigating mainly in an ethical context. Our study chose another line of approach, using, for the first time, fish scales as a matrix to measure cortisol in two wild marine fish, skipjack, and yellowfin tuna (male and female), in order to describe the causal effects of size and location on this indicator.

\section{Materials and methods}

The sample for the study was based on individuals from two tuna species, YFT and SKJ, captured by handline around anchored fish-aggregating devices (FADs) in the Atlantic (Gulf of Guinea off the Ivory Coast) and the Indian Ocean (off Reunion Island) (Fig. 1A and B) on 10-11 July and 26-29 September 2018, respectively. The total time between the bite on the hook and the killing of a tuna was between 2 and $10 \mathrm{~min}$. To minimize the pain, we euthanized the animals as soon as they were boarded, with a blow to the head that immediately killed the tuna (following European directive 2010/63/UE). The number of fish sampled was $n=22$ in the Gulf of Guinea (16 YFT, 6 SKJ) and $n=23$ off Reunion Island (9 YFT, 14 SKJ).

Onboard, the fork length ( $\mathrm{FL}$ in $\mathrm{cm}$, from the tip of the upper jaw to the caudal fin fork) and body mass (W in $\mathrm{kg}$ ) were measured by scientists. Scale samples (under the pectoral fin) were taken by scraping the flank with a blunt scalpel and these were collected in plastic Eppendorf tubes, which were immediately immersed in liquid nitrogen and stored at $-80{ }^{\circ} \mathrm{C}$ until analysis. The handlers wore gloves during the entire process to avoid external contamination.

The cortisol extraction from the scale samples $(n=45)$ was adapted from two different protocols (Aerts and De Saeger 2017; Carbajal et al. 2018). 


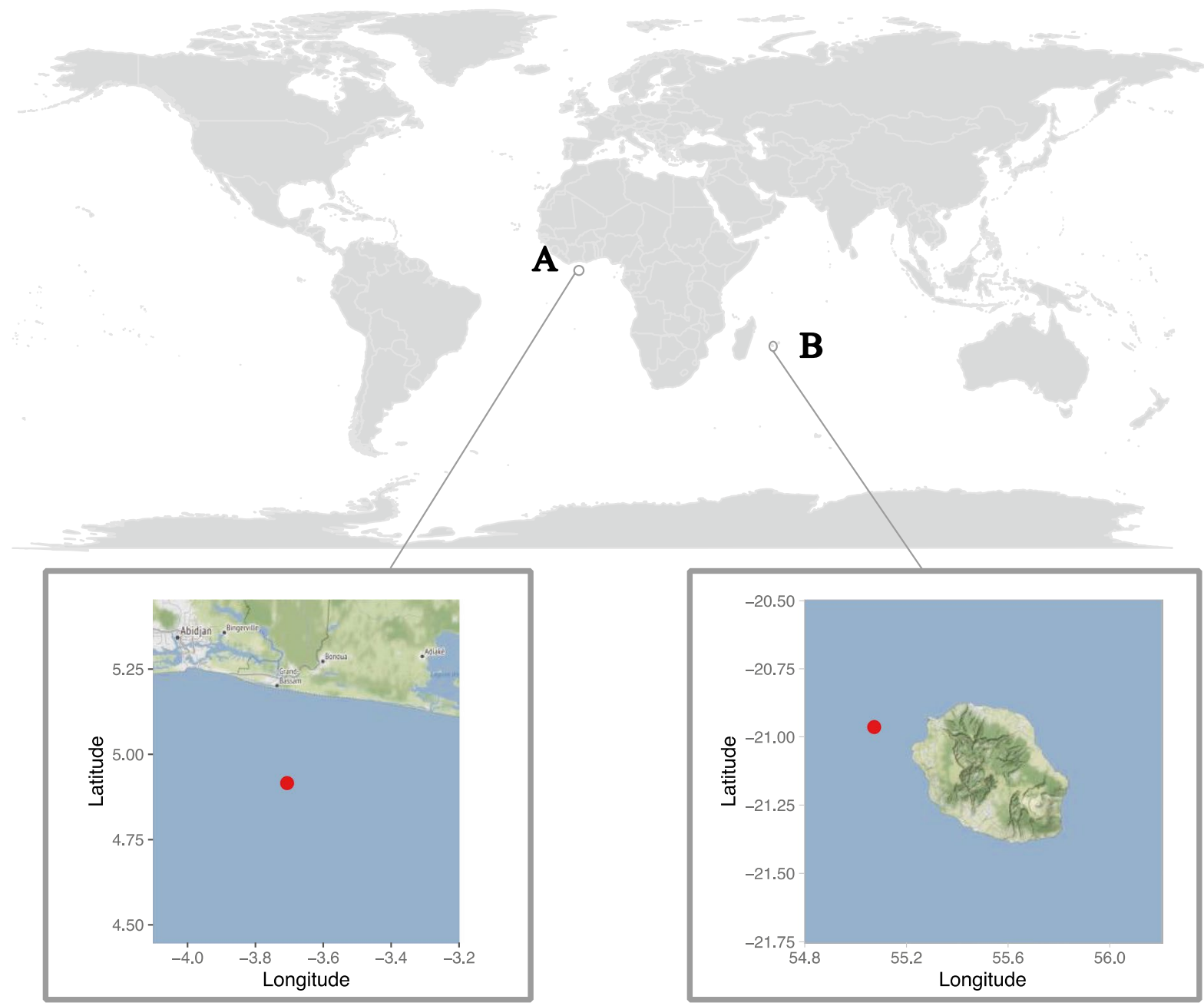

Fig. 1 Tuna species. Skipjack (Katsuwonus pelamis) and yellowfin (Thunnus albacares) were sampled in (A) the Gulf of Guinea (Atlantic Ocean), 27 nautical miles off Abidjan (Ivory Coast) in July 2018 and (B) La Réunion Island (Indian Ocean),

Scales were washed by adding $1.5 \mathrm{~mL}$ of isopropanol in each tube, agitated with a ceramic ball mill at $10 \mathrm{~Hz}$ for $3 \mathrm{~min}$ in a Retsch MM 400 tissuelyzer, and centrifuged at $14,000 \mathrm{~g}$ and $4{ }^{\circ} \mathrm{C}$ for 1 min. The supernatant was then discarded. This washing process was repeated three times to fully remove the covering mucus. The samples were then stored at $-20{ }^{\circ} \mathrm{C}$ for $1 \mathrm{~h}$ and lyophilized $(2 \mathrm{~h}$ freezing phase down to $-40{ }^{\circ} \mathrm{C}$, followed by a rapid increase up to $40{ }^{\circ} \mathrm{C}$ lyophilization phase in a 1000 mbar vacuum overnight). Once dried, subsamples were aliquoted in a new 2-mL Eppendorf tube and precisely weighed (mean weight and SE
10 nautical miles from shore, in September 2018. Red dots indicate the sampling location of the fish aggregating devices (FAD) where tunas have been captured

$95.5 \pm 9 \mathrm{mg}$ ). One ceramic mill ball was then added to each tube and samples were minced to powder in the tissuelyzer for $1 \mathrm{~min}$ at $30 \mathrm{~Hz}$. Cortisol extraction was performed by adding $1 \mathrm{~mL}$ of methanol to each tube, vortexed for $10 \mathrm{~s}$, and shaken overnight $(18 \mathrm{~h})$ at room temperature. Then, the samples were centrifuged at $12,000 \mathrm{~g}$ for $3 \mathrm{~min}$, and the supernatant transferred to a borosilicate glass evaporation tube. This last step was repeated after adding $1 \mathrm{~mL}$ of methanol to ensure maximum cortisol extraction. The contents of the glass tube were then evaporated to dryness by nitrogen flow at $40{ }^{\circ} \mathrm{C}$ using a MULTIVAP ${ }^{\circledR}$ Nitrogen evaporator (Organomation ${ }^{\circledR}$ ). 
All samples were then reconstituted in $150 \mu \mathrm{L}$ of $0.01 \%$ bovine serum albumine (BSA) in phosphate buffered saline solution (PBS - 2.7 M KCl; 0.137 M $\mathrm{NaCl} ; 1.8 \mathrm{mM}$ KH2PO4; Na2HPO4), vortexed 3 times for $15 \mathrm{~s}$, and stored at $4{ }^{\circ} \mathrm{C}$ until the ELISA assay. The cortisol was quantified using a competitive ELISA measurement described in Faught et al. (2016) and adapted from a protocol validated for zebrafish (Danio rerio) (Yeh et al. 2013). This involved coating 96-well plates with a cortisol monoclonal antibody $\left(1.6 \mu \mathrm{g} \mathrm{mL}^{-1}\right.$; East Coast Bio, ME, USA) in PBS and storing them at $4{ }^{\circ} \mathrm{C}$ for $16 \mathrm{~h}$. The cross-reactivity of the antibody is $0.4 \%$ for cortisone, $7.7 \%$ for 11 -deoxycortisol, and $21.9 \%$ for corticosterone (Sadoul and Geffroy 2019). While this is a high level of cross-reactivity with corticosterone, it should be noted that levels of this hormone have been reported to be relatively low in fish (at least 10 times lower than cortisol, as measured in plasma) (Kiilerich and Prunet 2011), so the specificity of the monoclonal antibody used here and in other fish studies (Yeh et al. 2013; Faught et al. 2016; Best et al. 2017) should only marginally change results. Standards were obtained by serially diluting hydrocortisone (Sigma) in PBS (0-25 $\mathrm{ng} \mathrm{mL}^{-1}$ ), and $50 \mu \mathrm{L}$ of either standards or samples were added to the wells in duplicate. Each well then received cortisol conjugated with horseradish peroxidase (HRP) and filled with a detection solution that turns blue when in contact with HRP. Sulfuric acid (1 N) was used to stop the reaction. Absorption was read at 450 nm (EL800 Universal Microplate Reader, BIOTEK INSTRUMENTS, INC.). Cortisol ELISA con-

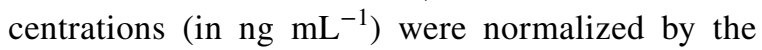
sample weight of each sample (expressed in ng of cortisol per $\mathrm{g}$ of scales). The intra-assay $\mathrm{CV}$ for the two plates was below $10 \%$. The standard curve was performed with $0.5,1,2,5$, and $10 \mathrm{ng} \mathrm{mL}^{-1}$, and the cortisol concentration measured in the scales was correlated with expected cortisol values for plate $1\left(r^{2}=0.95\right)$ and plate $2\left(r^{2}=0.98\right)$.

We first compared cortisol concentration in scales between species caught at the same site and tested for a potential fish-size effect. Then, we pooled all the data together to test whether the cortisol concentration in scales varied as a function of size, location, or species in the same linear mixed model. We added the ELISA plate as a random factor, as samples were run on separate ELISA plates. The interaction was removed from the model when not significant. To ensure that all fixed effects were taken into account similarly, we used a type II analysis of variance with Satterthwaite's method. All statistical analyses were performed using R software 3.2.2 ( $\mathrm{R}$ Development Core Team 2013) and package "Ime4" for linear mixed models (Bates et al. 2015). Maps were designed using the "ggmap" package (Kahle and Wickham 2013).

\section{Results and discussion}

We did not detect significant differences in cortisol concentration in scales as a function of fish length for either species (YFT $t=-0.24 ; p=0.8$; SKJ $t=-0.14 ; p=0.9$ ) (Table 1). Within each site, the cortisol concentration in SKJ scales was higher (although not significantly) than that in YFT scales ( $p=0.17$ in the Gulf of Guinea and $p=0.09$ off Reunion Island), so that when pooling all individuals together in the model accounting for all fixed effects (Cortisol $\sim$ Location + Length + Species + (1|PlateScales)), cortisol concentration was significantly higher $(t=1.97 ; p=0.0558)$ in SKJ scales compared to YFT scales, independently of their size and location (Fig. 2). However, it is worth

Table 1 Biometrics data (number, length, weight) of the two tuna species (sp), skipjack (SKJ, Katsuwonus pelamis), and yellowfin (YFT, Thunnus albacares)

\begin{tabular}{llllllllll}
\hline & $\mathrm{sp}$ & $\mathrm{nb}$ & $\delta$ & $q$ & $\mathrm{ND}$ & $\begin{array}{c}\text { Length }(\mathrm{cm}) \\
\text { min-max }\end{array}$ & $\begin{array}{c}\text { Length }(\mathrm{cm}) \\
\text { average } \pm \text { SD }\end{array}$ & $\begin{array}{l}\text { Weight (kg) } \\
\text { min-max }\end{array}$ & $\begin{array}{c}\text { Weight }(\mathrm{kg}) \\
\text { average } \pm \text { SD }\end{array}$ \\
\hline Gulf of Guinea & YFT & 16 & 7 & 6 & 3 & $46.5-66$ & $58.08 \pm 5.22$ & $1.6-4.6$ & $3.13 \pm 0.87$ \\
Gulf of Guinea & SKJ & 6 & 3 & 3 & 0 & $56-66$ & $59.78 \pm 3.95$ & $2.9-4.4$ & $3.52 \pm 0.52$ \\
La Réunion Island & YFT & 9 & 3 & 6 & 0 & $61.5-69.6$ & $64.61 \pm 2.77$ & $4.1-5.5$ & $4.51 \pm 0.45$ \\
La Réunion Island & SKJ & 14 & 4 & 10 & 0 & $41.4-60$ & $51.57 \pm 5.62$ & $1.2-4.0$ & $2.45 \pm 0.79$ \\
\hline
\end{tabular}


Fig. 2 Cortisol concentrations $\left(\mathrm{ng} \mathrm{g}^{-1}\right)$ measured in the scales of the two tuna species $K$. pelamis $(\mathrm{SKJ})$ and $T$. albacares (YFT), in the Atlantic and Indian oceans, correlated to the fish length (in $\mathrm{cm}$ )

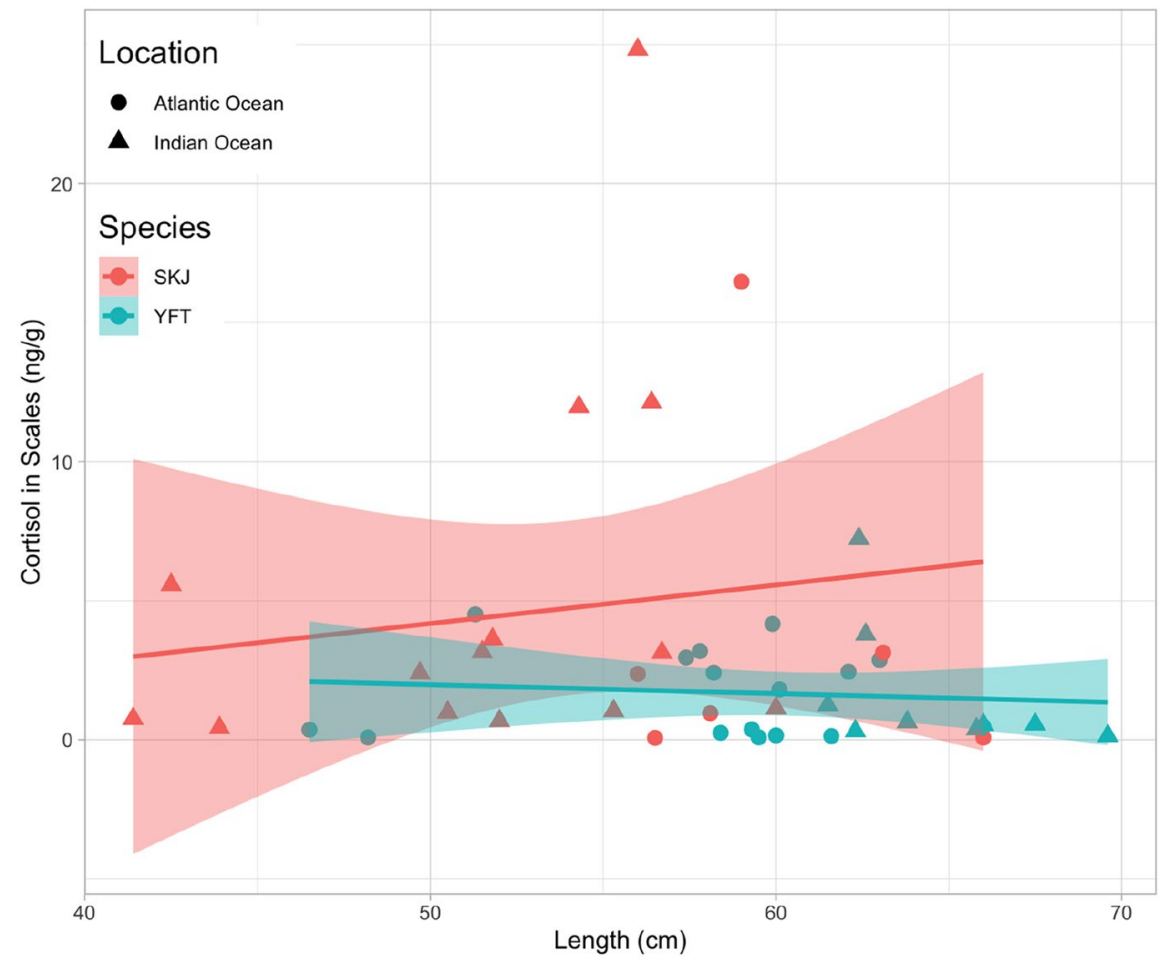

noting that this pattern was driven by 4 SKJ individuals between 54 and $59 \mathrm{~cm}$ in FL (3 individuals from Reunion Island and 1 individual from the Gulf of Guinea). According to the sampling size of this study, neither the size:species interactions nor the size:location interactions were found to be significant ( $p=0.5 \& 0.6$, respectively).

Cortisol in scales has been proven to be an effective marker of chronic stress in various fish species (Aerts et al. 2015; Carbajal et al. 2019; Laberge et al. 2019; Hanke et al. 2020). Yet, the mechanisms of cortisol clearance in scales are not well described, and to our knowledge, only one recent study on goldfish (Carassius auratus) has provided insights regarding its rate (Laberge et al. 2019). That study demonstrated that following a cortisol treatment, plasma levels went back to initial values after only 3 days, while it took 27 days to return to the basal level in scales. This implies that cortisol is somehow catabolized at a much slower rate in scales than in plasma, likely because this steroid is embedded in calcified structures that protect it. The cortisol values found for both species in our study were well within the range of those reported for other fish species, e.g., European seabass (Dicentrarchus labrax) (from 1.7 to $3.4 \mathrm{ng} \mathrm{g}^{-1}$, Aerts and De Saeger 2017) and goldfish (Carassius auratus) (from 0.25 to $2.10 \mathrm{ng} \mathrm{g}^{-1}$, Carbajal et al. 2018). Although our study relied on a small dataset, the cortisol concentrations in scales were significantly higher in skipjack (mean $4.75 \pm 6.56 \mathrm{ng} \mathrm{g}^{-1}$ ) than in yellowfin (mean $1.65 \pm 1.85 \mathrm{ng} \mathrm{g}^{-1}$ ) for individuals of the same size. Interestingly, the cortisol concentration did not increase with fish size (i.e., age), which argues for a slow-but active-renewal of cortisol in this matrix, as demonstrated by Laberge et al. (2019), rather than an accumulation over time.

Adult skipjack and juvenile yellowfin tuna (the size classes sampled in our study) are known to share many anatomical, physiological, and behavioral similarities. They have similar swimming modes, thermal biology, increased rate functions (e.g., standard metabolic rate, aerobic capacity, heart rate, and gut clearance), and cardiac physiology (Graham and Dickson 2004), which distinguish them from many other teleost species. They have the same vertical habitat utilization (Schaefer et al. 2009) and usually feed on the same prey species (Jaquemet et al. 2011), although some diet differences have been observed in specific oceanic regions (Olson et al. 2016). They both form 
large schools and associate with floating objects, but differences in their fine-scale FAD-associative behavior have been observed (Rodriguez-Tress et al. 2017). Considering the strong similarities between these two species, one might expect similar cortisol metabolism, resulting in similar concentrations of cortisol in scales. Larger datasets are needed to confirm the differences between these two species. In parallel, experiments on captive tuna should be conducted in order to investigate the time evolution of cortisol concentration over several days and weeks. If a species difference in cortisol concentration is confirmed by larger datasets, this may be explained by speciesspecific cortisol metabolism. This would imply intrinsic differences in the production and/or clearance of cortisol (dependent upon cortisol-binding proteins, target tissue receptors, tissue uptake, and catabolism of cortisol) (Mommsen et al. 1999). The production/ clearance of cortisol and the rate of scale formation (and therefore the associated integration of cortisol) in these two species have not yet been investigated and represent a perspective for future studies.

In our dataset, however, the difference in cortisol concentration observed between the two species was mainly due to four skipjack individuals. Interestingly, comparable high values were also detected in some extremely stressed European seabass (Aerts and de Saeger 2017) and goldfish (Laberge et al. 2019). These high concentrations of cortisol in scales may be the consequence of specific stressful events experienced by these individuals, such as attacks by predators or fasting periods that might have occurred over the preceding days or weeks. Understanding why some individuals of the same species and the same size, in the same fish aggregation around a FAD, have significantly higher concentrations of cortisol (about five times higher) would be valuable to study on a physiological and behavioral level. Considering that the clearance rate of cortisol in scales is very slow, it may be that individuals with high concentrations of cortisol belong to different schools than the fish with lower cortisol concentrations. Tuna aggregations at FADs usually consist of several schools (Josse et al. 2000; Dagorn et al. 2007; Moreno et al. 2007). As fish from the same school are likely to have a relatively long common history (although the stability of a tuna school appears to vary quite a lot, see Bayliff 1988 and Hilborn 1991), it can be assumed that fish from the same school have comparable concentrations of cortisol as they have usually experienced the same events. This hypothesis could be investigated by comparing intra- and inter-school variability of cortisol concentrations in individuals of the same species sampled from different free-swimming schools caught by purse seiners (as sampling tuna associated with FADs does not ensure that they are from the same school).

\section{Conclusion}

This preliminary study provides the first measurements of cortisol in the scales of wild tuna. While further studies are needed to better understand the mechanisms of scale cortisol clearance and metabolism in the selected species (e.g., a comparison of the cortisol level in scales and in other biological matrices: mucus, plasma, muscle, etc.), this data offers a good start for designing new experiments. In the same way, Willis and Hobday (2008) suggested taking bioelectrical impedance analysis (BIA) measurements to measure the condition of tuna during tagging operations; we suggest sampling a few scales from individuals during conventional or electronic tagging. This would be a quick and harmless operation that should not disrupt tagging operations and would allow measuring the markers of chronic stress (as opposed to the stress due to capture, measured by cortisol in plasma) of tagged individuals. Comparing the largescale movements (from conventional or archival tags) or the fine-scale movements within arrays of FADs (from acoustic tags) for fish with different concentrations of cortisol would provide key insights into the ecology of these species, particularly the possible links between stress response and behavior.

Acknowledgements The sampling and slaughtering of animals were carried out by professional fishermen working for the French National Research Institute for Sustainable Development (IRD) Exploited Tropical Pelagic Ecosystems Observatory, which is ISO 9001:2015 certified.

The authors would also like to thank the professional fishermen from La Réunion Saint Gilles Fishing Club for their help in fish sampling. We also thank Aurélie Guillou (IRD), who assisted us in sampling some specimens. We are grateful to Antoinette Adingra, Nadège Kouadio, and Constance Diaha, colleagues from the Oceanology Research Center of Abidjan, for their contribution in the fish sex assessment.

Finally, many thanks to the editor (Dr. Margaret Docker) and referees, who provided very constructive comments on the 
initial version of this manuscript, and to Elise Bradbury for the English proofreading.

Author contribution E.R.O. and B.G. designed the study, E.R.O., Y.B., and T.B. collected the samples, and M.D., B.S, B.G., and E.R.O. performed the analyses. All authors prepared the manuscript and approved its submission.

Funding The Tuna MicrobiOME project (THE MOME) receives funding from Montpellier University of Excellence (MUSE) and the Marine Biodiversity and Conservation (MAR$\mathrm{BEC})$ research group.

\section{Declarations}

Ethics approval All sampling and animal handling respected good scientific practice and animal welfare rules. To minimize suffering, we euthanized the animals as soon as they were boarded. The number of fish sampled was limited to the strict number necessary.

Consent to participate Not applicable.

Consent for publication Not applicable.

Conflict of interest The authors declare no competing interests.

\section{References}

Addis P, Corrias S, Garau C, Secci M (2013) Physiologic responses to stress and changes in Atlantic bluefin tuna (T. thynnus) meat color during trap fisheries capture and processing in Sardinia (W. Mediterranean). J Aquat Food Prod Technol 22:298-309. https://doi.org/10.1080/10498 850.2011 .647596

Aerts J, Metz JR, Ampe B, Decostere A, Flik G, Saeger SD (2015) Scales tell a story on the stress history of fish. PLoS ONE 10:e0123411. https://doi.org/10.1371/journal. pone.0123411

Aerts J, De Saeger S (2017) Quantification of glucocorticoids in fish scales as biomarkers for chronic stress. United States Patent 9, 638, 703 B2

Barton BA (2002) Stress in fishes: a diversity of responses with particular reference to changes in circulating corticosteroids. Integr Comp Biol 42:517-525. https://doi.org/10. 1093/icb/42.3.517

Bates D, Maechler M, Bolker B, Walker S (2015) Fitting linear mixed-effects models using lme4. J Stat Softw 67: 1-48. https://doi.org/10.18637/jss.v067.i01

Bayliff WH (1988) Integrity of schools of skipjack tuna, Katsuwonus pelamis, in the eastern Pacific Ocean, as determined from tagging data. Fish Bull NOAA-NMFS 86(4):631-643

Best C, Kurrasch DM, Vijayan MM (2017) Maternal cortisol stimulates neurogenesis and affects larval behaviour in zebrafish. Sci Rep 7(1):1-10. https://doi.org/10.1038/ srep40905

Carbajal A, Monclús L, Tallo-Parra O, Sabes-Alsina M, Vinyoles D, Lopez-Bejar M (2018) Cortisol detection in fish scales by enzyme immunoassay: biochemical and methodological validation. J Appl Ichthyol 34:967-970. https://doi.org/10.1111/jai.13674

Carbajal A, Reyes-López FE, Tallo-Parra O, Lopez-Bejar M, Tort L (2019) Comparative assessment of cortisol in plasma, skin mucus and scales as a measure of the hypothalamic-pituitary-interrenal axis activity in fish. Aquaculture 506:410-416. https://doi.org/10.1016/j.aquaculture. 2019.04.005

Dagorn L, Holland KN, Itano DG (2007) Behaviour of yellowfin (Thunnus albacares) and bigeye (T. obesus) tuna in a network of fish aggregating devices (FADs). Mar Biol 151:595-606. https://doi.org/10.1007/s00227-006-0511-1

Ellis T, Yildiz HY, LópezOlmeda J, Spedicato MT, Tort L, Øverli Ø, Martins CIM (2012) Cortisol and finfish welfare. Fish Physiol Biochem 38:163-188. https://doi.org/ 10.1007/s10695-011-9568-y

FAO (2018) The state of world fisheries and aquaculture. FAO Fisheries and Aquaculture Technical Paper

Faught E, Best C, Vijayan MM (2016) Maternal stress-associated cortisol stimulation may protect embryos from cortisol excess in zebrafish. R Soc Open Sci 3(2):160032. https://doi.org/10.1098/rsos.160032

Goikoetxea A, Sadoul B, Blondeau-Bidet E, Aerts J, Blanc MO, Parrinello H, Geffroy B (2020) Genetic pathways underpinning hormonal stress responses in fish exposed to short-and long-term warm ocean temperatures. Ecol Indic 120:106937. https://doi.org/10.1016/j.ecolind.2020. 106937

Graham JB, Dickson KA (2004) Tuna comparative physiology. J Exp Biol 207(Pt 23):4015-4024. https://doi.org/10. 1242/jeb.01267

Hanke I, Hassenrück C, Ampe B, Kunzmann A, Gärdes A, Aerts J (2020) Chronic stress under commercial aquaculture conditions: scale cortisol to identify and quantify potential stressors in milkfish (Chanos chanos) mariculture. Aquaculture 526:735352. https://doi.org/10.1016/j. aquaculture.2020.735352

Hilborn R (1991) Modeling the stability of fish schools: exchange of individual fish between schools of skipjack tuna (Katsuwonus pelamis). Can J Fish Aquat Sci 48:1081-1091. https://doi.org/10.1139/f91-128

Jaquemet S, Portier M, Ménard F (2011) Do drifting and anchored fish aggregating devices (FADs) similarly influence tuna feeding habits? A case study from the western Indian Ocean. Fish Res 107:283-290. https://doi.org/10. 1016/j.fishres.2010.11.011

Josse E, Dagorn L, Bertrand A (2000) Typology and behaviour of tuna aggregations around fish aggregating devices from acoustic surveys in French Polynesia. Aquat Liv Resour 13:183-192

Kahle D, Wickham H (2013) ggmap: Spatial Visualization with ggplot2. R J 5(1):144-161

Kiilerich P, Prunet P (2011) Corticosteroids, In: Encyclopedia of fish physiology: from genome to environment. Volume 2. Gas exchange, internal homeostatis, and food uptake. Academic Press - Elsevier, London, pp 1474-1482 
Kirchhoff NT, Leef MJ, Ellis D, Purser J, Nowak BF (2011) Effects of the first two months of ranching on the health of southern bluefin tuna Thunnus maccoyii. Aquac 315:207-212. https:// doi.org/10.1016/j.aquaculture.2011.02.036

Koolhaas JM, Korte SM, De Boer SF, Van Der Vegt BJ, Van Reenen CG, Hopster H, De Jong IC, Ruis MAW, Blokhuis HJ (1999) Coping styles in animals: current status in behavior and stress-physiology. Neurosci Biobehav Rev 23(7):925-935. https://doi.org/10.1016/S0149-7634(99) 00026-3

Laberge F, Yin-Liao I, Bernier NJ (2019) Temporal profiles of cortisol accumulation and clearance support scale cortisol content as an indicator of chronic stress in fish. Conserv Physiol 7(1): coz052. https://doi.org/10.1093/conphys/ coz052

Mommsen T, Vijayan M, Moon T (1999) Cortisol in teleosts: dynamics, mechanisms of action, and metabolic regulation. Rev Fish Biol Fish 9(3):211-268. https://doi.org/10. 1023/A:1008924418720

Moreno G, Dagorn L, Sancho G, Itano D (2007) Fish behaviour from fishers' knowledge: the case study of tropical tuna around drifting fish aggregating devices (DFADs). Can J Fish AquatSci 64: https://doi.org/10.1139/F07-113. https://doi.org/10.1139/F07-113.10.1139/F07-113

Olson RJ, Young JW, Ménard F, Potier M, Allain V, Goñi N, Logan JM, Galván-Magaña F (2016) Chapter four - bioenergetics, trophic ecology, and niche separation of tunas. Adv Mar Biol 74:199-344. https://doi.org/10.1016/bs. amb.2016.06.002

Øverli $\varnothing$, Pottinger TG, Carrick TR, Øverli E, Winberg S (2002a) Differences in behaviour between rainbow trout selected for high- and low-stress responsiveness. J Exp Biol 205:391-395. https://doi.org/10.1242/jeb.205.3.391

Øverli Ø, Kotzian S, Winberg S (2002b) Effects of cortisol on aggression and locomotor activity in rainbow trout. Horm Behav 42:53-61. https://doi.org/10.1006/hbeh.2002.1796

R Development Core Team (2013) R: A language and environment for statistical computing. R Foundation for Statistical Computing, Vienna, Austria

Rodriguez-Tress P, Capello M, Forget F, Soria M, Beeharry SP, Dussooa N, Dagorn L (2017) Associative behavior of yellowfinThunnus albacares, skipjack Katsuwonus pelamis and bigeye tuna Thunnus obesus at fish aggregating devices (FADs) off the coast of Mauritius. MEPS 570. https://doi.org/10.3354/meps12101
Sadoul B, Geffroy B (2019) Measuring cortisol, the major stress hormone in fishes. J Fish Biol 94(4):540-555. https://doi.org/10.1111/jfb.13904

Sadoul B, Vijayan MM (2016) 5-stress and growth. In C. B. Schreck, L. Tort, A. P. Farrell, \& C. J. Brauner (Éd.), Fish Physiol 35: 167-205 Academic Press

Schaefer KM, Fuller DW, Block BA (2009) Vertical movements and habitat utilization of skipjack (Katsuwonus pelamis), yellowfin (Thunnus albacares), and bigeye (Thunnus obesus) tunas in the equatorial eastern Pacific Ocean, ascertained through archival tag data. In: Nielsen J.L., Arrizabalaga H., Fragoso N., Hobday A., Lutcavage M., Sibert J. (eds) Tagging and Tracking of Marine Animals with Electronic Devices. Reviews: Methods and Technologies in Fish Biol Fish 9. Springer, Dordrecht. https://doi.org/10.1007/s00227-010-1524-3

Schreck CB, Tort L (2016) The concept of stress in fish. In: Schreck CB, Tort L, Farrell AP, Brauner CJ. Fish Physiology, Academic Press 35:1-4

Skomal GB (2007) Evaluating the physiological and physical consequences of capture on post-release survivorship in large pelagic fishes. Fish Manag Ecol 14:81-89. https:// doi.org/10.1111/j.1365-2400.2007.00528.x

Tracey S, Hartmann K, Mc Allister J, Conron S, Leef M (2016) Capture-induced physiological stress and post-release survival of recreationally caught Southern Bluefin Tuna. Can J Fish Aquat Sci 73 (10). https://doi.org/10.1139/ cjfas-2015-0516

Willis J, Hobday AJ (2008) Application of bioelectrical impedance analysis as a method for estimating composition and metabolic condition of southern bluefin tuna (Thunnus maccoyii) during conventional tagging. Fish Res 93(12):64-71. https://doi.org/10.1016/j.fishres.2008.02.010

Yeh CM, Glöck M, Ryu S (2013) An optimized whole-body cortisol quantification method for assessing stress levels in larval zebrafish. PLoS ONE 8:e79406. https://doi.org/10. 1371/journal.pone.0079406

Publisher's note Springer Nature remains neutral with regard to jurisdictional claims in published maps and institutional affiliations. 